\title{
Pánico a la discoteca: Teatro, transición y underground (Chile, época 1990)
}

Panic to the disco: theater, transition, and underground (Chile, circa 1990)

Pânico à discoteca: teatro, transição e underground (Chile, época 1990)

\section{Cristián Opazo}

PONTIFICIA UNIVERSIDAD CATÓLICA DE CHILE, CHILE

Profesor Asociado en el Departamento de Literatura de la Pontificia

Universidad Católica de Chile. Doctor en Literatura por esa misma casa de estudios. Actualmente, investiga sobre las relaciones entre teatro, disidencia sexual y culturas urbanas. Es autor de Pedagogías letales: ensayo sobre dramaturgias chilenas del nuevo milenio (Cuarto Propio, 2011); y, coeditor - junto con Carola Oyarzún- de varios volúmenes sobre dramaturgia chilena: Heiremans (Ediciones UC, 2012), Siete obras desconocidas de forge Díaz (Ediciones UC, 2013), Galemiri (Ediciones UC, 2017). Correo electrónico: cmopazo@uc.cl

Artículo de reflexión

Este trabajo forma parte del proyecto FONDECYT 1150483, "Escenarios contra-pedagógicos: dramaturgias chilenas más allá de los teatros universitarios", del que soy investigador responsable.

Documento accesible en línea desde la siguiente dirección: http://revistas.javeriana.edu.co 


\section{Resumen}

En este ensayo analizo un performance de resistencia contracultural celebrado en Santiago de Chile, en plena transición democrática: Spandex, serie de ocho fiestas underground organizadas, en el invierno de 1991, por los teatristas Daniel Palma y Andrés Pérez, como estrategia de sobrevivencia para su propia compañía, el Gran Circo Teatro. A partir de la revisión de archivos de prensa, expongo los mecanismos de censura - con énfasis en el género y las sexualidades-que se ciernen sobre Spandex, y el programa del gobierno transicional al que estos mecanismos responden.

Palabras clave: Andrés Pérez; Daniel Palma; Gran Circo Teatro; teatro chileno; transición democrática-aspectos culturales

\section{Abstract}

In this essay I analyze a countercultural resistance performance held in Santiago de Chile, in the middle of the democratic transition; Spandex, a series of eight underground festivals held in the winter of 1991 by theater-workers Daniel Palma and Andrés Pérez as a survival strategy for their own company, the Great Circus Theater. Based on the review of press archives, I expose the censorship mechanisms, emphasizing on gender and sexualities, that hang over Spandex and the transitional government program to which these mechanisms respond.

Keywords: Andrés Pérez; Daniel Palma; Great Circus Theater; Chilean theater; democratic transition-cultural aspects

\section{Resumo}

Neste ensaio analiso um performance de resistência contracultural que decorreu em Santiago do Chile, no meio da transição democrática: Spandex, serie de oito festas underground organizadas, no inverno de 1991, pelos teatreiros Daniel Palma e Andrés Pérez, como estratégia de sobrevivência para a sua mesma companhia, o Gran Circo Teatro. A partir da revisão de arquivos de imprensa, exponho os mecanismos de censura — com ênfase no gênero e as sexualidades-que se cernem sobre Spandex e o programa do governo transicional a que estes mecanismos respondem.

Palavras-chave: Andrés Pérez; Daniel Palma; Gran Circo Teatro; teatro chileno; transicao democrática-aspetos culturais

Cómo citar este artículo:

Opazo, Cristián. "Pánico a la discoteca: Teatro, transición y underground (Chile, época 1990)".

Cuadernos de Literatura 21.42 (2017): 49-66. https://doi.org/10.11144/Javeriana.cl21-42.pdtt 
"Me vestía como fleto: me peinaba el pelo para adentro y me echaba tulica en las pestañas. Iba para maricón de puerto que ni te explico. Además, desde la ignorancia, también me preguntaba: ¿qué puede hacer uno como maricón? Un maricón no podía estudiar pedagogía o medicina, ni tampoco podía trabajar de chofer de micro. ¿Qué hacía un maricón en la vida?" DANIEL PALMA, EN ENTREVISTA CON OGTAVIO CRESPO.

\section{Los chicos Spandex}

Sábado en la noche. Brigadas policiales patrullan la ciudad. Un piquete de caras pintadas allana cines, desaloja fiestas, vigila teatros. En pleno gobierno cívico-militar de Patricio Aylwin Azócar (1990-1994), clérigos, empresarios, intelectuales-orgánicos, militares, políticos y torturadores sufren de "pánico a la discoteca". ' Si no, que lo digan, también, el escenógrafo de teatro y televisión Daniel Palma (Montevideo, 1960) y el director y dramaturgo Andrés Pérez Araya (Punta Arenas, 1951-Santiago, 2002), ya que, entonces, son ellos los cabecillas de una subversiva célula de resistencia contra-cultural, Spandex Fiesta: serie de ocho espectáculos underground celebrados en el teatro Esmeralda de Santiago (San Diego 1035), la madrugada de cada sábado de mayo y junio de ese tan opaco invierno del noventa y uno. ${ }^{2}$

Además de extraviar sus cuerpos en una ciudad que todavía vive bajo la amenaza de escaramuzas militares, ${ }^{3}$ con Spandex, Palma y Pérez buscan

1 Cuando digo "pánico a la discoteca", pienso en la evidencia que recopila el documental Chile en llamas: el arte de la censura (2015), de Carmen Luz Parot. Allí, la directora exhibe cómo, en plena transición democrática, los poderes castrenses, eclesiásticos y políticos realizan escarnio público de los agentes culturales que conciben las artes convivales, siempre festivas, como espacios para la discusión sobre las libertades individuales en los territorios de los derechos reproductivos, el género y la sexualidad.

2 Cada fiesta de la serie se desarrolla a partir de una consigna provocadora: además de Spandex (4 de mayo), se celebran Noche de Negros (11 de mayo), 70 a la Chilena con intervención rusa (18 de mayo), El Caribe Nunca tan Lejos (25 de mayo), Made in Ingland [sic] (1 de junio), Noche de Estrellas (8 de junio), La Noche del Verbo (15 de junio) y Noche de Época: La Nuestra (22 de junio).

3 Piénsese, por ejemplo, en episodios tales como los denominados Ejercicios de Enlace (19 de diciembre 1990) o El Boinazo (28 de mayo de 1993), dos operaciones militares en que comandos del Ejército se movilizan en las afueras de las principales ciudades del país y frente al palacio de gobierno, respectivamente. A través de estas acciones armadas, Augusto Pinochet, 
financiar, mediante la venta de entradas de 1000 pesos (unos 1,2 USD de la actualidad), los nuevos proyectos del Gran Circo Teatro, la compañía independiente que allí los cobija. En el verano del noventa y dos, sueñan con montar King Richard the Second (1595) y Twelfth Night (1602), de W. Shakespeare, en versión kathakali. Además, imaginan completar la segunda etapa de la restauración del Esmeralda. ${ }^{4}$ Esta vez, anhelan convertirlo en un laboratorio de investigación teatral abierto a esos agentes culturales que no caben dentro de las desmanteladas aulas universitarias.

Con el afán contrapedagógico de hacer virales — como el VIH/SIDA que los acecha - los saberes que las universidades proscriben, los chicos Spandex proyectan espectáculos cuya teatralidad está inspirada en los clubes metropolitanos que conocen, casi siempre, de oídas: el Blitz de Londres, el Hacienda de Mánchester o el Studio 54 de Nueva York. ${ }^{5}$ Así inspirados, en cada noche de fiesta, Palma y Pérez establecen un cuidado programa que, entre las 12:00 y 6:00 a.m., incluye playlists con música de vanguardia, sobre todo, acid house envasado en casetes piratas traídos por Palma desde Mánchester y Nueva York en las giras del Gran Circo Teatro; coreografías de gogo dancers que, ataviados con prendas halladas en la tienda de ropa reciclada Cero 9o, enseñan a decir con el cuerpo los afectos de los homosexuales penados por

aún en el cargo de comandante en jefe del Ejército, ejerce presión sobre las nuevas autoridades civiles que amenazan con investigar los delitos económicos y de lesa humanidad perpetrados durante su régimen.

Hallado en ruinas por Pérez, el Teatro Esmeralda es el primero de los cines o teatros "palacio" de Santiago: proyectado con una capacidad de 2600 personas, y magníficos foyer y conjunto de palcos estilo Art Déco, el Esmeralda es epicentro teatral en la década de 1920. Desde el comienzo, su escenario sabe de polémicas: se rumorea que el estreno de Homicidio (1918), drama social de Antonio Acevedo Hernández, termina con un allanamiento policial por lo escandaloso del argumento (acicate para la insurrección obrera). De seguro, Pérez, confeso admirador de Acevedo Hernández y, luego, director de su clásico Chañarcillo (1936), conoce esta historia cuando allí recala.

5 Los clubes aludidos son reputados entre los jóvenes chilenos que sobreviven a la dictadura: admiran a sus congéneres del Hemisferio Norte, en su mayoría de clase obrera, que articulan movimientos contraculturales que aúnan música pop, moda callejera y reivindicación de la disidencia sexual (el disco en Studio 54, el acid house en The Hacienda y el new romantic en Blitz). Para Palma, en especial, "[1]a ciudad clave fue Mánchester, donde ya estaba instalada la electrónica, los club[e]s, la cultura de los DJ y la mezcla de rock con música de baile que tan bien representaban bandas como Happy Mondays o Primal Scream en el club Hacienda" (Ramírez, par. 6). Tras girar por Inglaterra y Escocia con el Gran Circo Teatro, Palma sentencia: "[y]o no entré [a Hacienda], de puro gil [...] [pero] [l]a energía de ir a bailar y juntarte con todo tipo de gente es algo que me voló la cabeza" (citado en Ramírez, par. 7). 
el Artículo 365 del Código Penal chileno hasta 1999; irreverentes mediosmontajes que, sin duda, serían censurados por los teatros universitarios aún reacios a escenificar desnudos; y performances de transformistas senescentes que ironizan con "el chiste" (en jerga, el virus del VIH/SIDA), aun cuando las autoridades de salud - entre ellas el ministro Jorge Jiménez - parecen considerarlo cuestión de grupos de riesgo, "putas y maricones" (Contardo, "SIDA" par. 1$).{ }^{6}$

Con la emergencia de esta teatralidad residual, la ciudad entra en crisis. Los grupos de fundamentalistas cristianos saturan los tribunales con demandas por ofensas a la moral. Mientras tanto, los jóvenes creadores se fugan de sus escuelas porque dicen que, en el Esmeralda, se enseñan técnicas y formatos ausentes de sus planes de estudio (teatro-circo de Ariane Mnouchkine, el teatro-danza de Pina Bausch, el teatro kathakali de Kudamaloor Karunakaran Nair). ${ }^{7}$ Peor aún, alarmadas por la suerte de los pupilos descarriados, las autoridades civiles intuyen que, allí, puede encenderse un foco de propagación de enfermedades de transmisión sexual, narcotráfico, pedofilia y prostitución masculina que, para ellas, son lo mismo: "en ese minuto las cosas se hablaban asî" - recuerda Palma - "eran los maricones, las putas y Spandex [...] mucha gente se infectó por la teoría de que a los malos les daba SIDA" (citado en Crespo 168). Con Spandex — continúa - la institucionalidad, estatal y religiosa, "cambió su discurso de la reconciliación [democrática] por [el de] la crisis moral" suscitada por los "grupos de riesgo" que allí se citan (Palma citado en Alvarado, par. 41). Con ello, el pánico a la discoteca al fin se desata. De ahí en adelante, los parroquianos del Esmeralda deben aprender a tolerar los allanamientos semanales del Grupo de Operaciones Policiales Especiales

6 Como bien describe la periodista Constanza Iglesias, el "pulso" de Spandex era "parecid[o] al de una función [de teatro] itinerante": "[a]trás del escenario, se [puede] encontrar a artistas maquillándose, transformistas cambiando sus cuerpos". En el escenario y en la pista de baile, conviven de manera inédita artistas circenses (Los Hermanos Farfán), coreógrafos de ballet (Patricio Bunster), directores de escena (Ramón Griffero), diseñadores "alternativos" (Ricardo Oyarzún), divas de la década de 1960 (Cecilia La Incomparable), drag-queens (Carlos Franco / Divina Extravaganza), escenógrafos (Herbert Jonckers), transformistas de vieja escuela (Candy Dubois), junto con Palma y Pérez, que ofician de anfitriones, oradores y gogo dancers.

7 Parte clave de los asistentes son jóvenes venidos de familias acomodadas que, con esta "mala educación" a cuestas, en los años siguientes, conforman un grupo de celebridades que circula en los campos de las artes, la moda, la prensa y la televisión de la transición: Jordi Castell (fotógrafo), Rubén Campos (diseñador), Alfredo Castro (actor), Amaro Gómez-Pablos (periodista), Amparo Noguera (actriz), Consuelo Saavedra (periodista), Paulina Urrutia (actriz, ministra de Cultura durante el primer Gobierno de Michelle Bachelet) o Iván Valenzuela (periodista). 
de Carabineros de Chile (GOPE): "[i]ban tanto a las Spandex que ya eran parte del show. Estaban en pauta" — insiste Palma_. "Entre tres y tres y media, llegan los pacos. El show verde" (citado en Parot).

De una madrugada de invierno cualquiera (El Caribe Nunca tan Lejos [25 de mayo]), algunos asistentes entrevistados todavía oyen el eco de la voz estridente de un comando cara pintada que irrumpe en el foyer del Esmeralda: "¡Mujeres a la derecha, hombres a la izquierda!". Otros testigos agregan que se escuchó más fuerte la voz aflautada de una "loca" escudada en su sombrero de ala ancha y cinta de raso amarillo: " ¿Y nosotras?, ¿y nosotras, dónde?". Entre la música y las luces que, esa noche, nunca se apagaron, el comando observa cómo se yergue una tercera fila de afectados bailarines. Quién sabe. Los ecos de esa noche también se confunden con las imágenes de un VHS inédito. Difuminado por una nube de gas lacrimógeno y humo de cigarrillos, Pérez, vestido con chaqueta de cuero negro, sube al escenario, toma el micrófono y clausura la fiesta:

[v]amos a tener que desalojar. A la salida, carabineros los revisará uno por uno. Nosotros nos quedamos hasta el final [...] Y cuando lleguen los carabineros que van a entrar en este momento, nosotros también demostremos esa madurez, por favor. Yo no quisiera que este teatro se destruyera. Esta es nuestra fuente de trabajo. No quiero pánico [en esta discoteca] ni que se destruya la escenografía. Entonces, tranquilos todos por favor, los esperamos el próximo sábado. (citado en Parot)

Pero, claro, los editores sensacionalistas de El Mercurio, principales promotores del discurso de la crisis moral, no pueden aguardar y continúan el acoso. El martes de la semana siguiente, en la sección de actualidad nacional, publican una nota de advertencia firmada por Germán Echevarría: "Importan nuevos conceptos de diversión juvenil". A decir del pacato articulista, en el Esmeralda:

Es un mundo donde no existe la censura y en el cual lo convencional se convierte en ridículo y lo extravagante en normal [...] Ahí todos pueden dar cauce a sus más extrañas conductas [...] Ya no sorprende ver a muchachos con provocativos atuendos y maquillaje; a jovencitas saliendo del baño de varones; presenciar a niñas desmayadas por el efecto del alcohol o sentir un fuerte olor a marihuana [...] [allí, ya no se sabe si] esa niño o niña que está allá está estupendo o estupenda. 
Ante sus lectores escandalizados, Echeverría, afectado de manera evidente, culpa al exceso de maquillaje de los gogo dancers de hacerlo vacilar en su propio performance lingüístico del género (gramatical, claro está). Así sea. Pese a la ética cuasi punk de Palma y Pérez — "Do It Yourself" es la consigna - las intrigas políticas, rápidamente, asaltan esta improvisada pista de bailes clandestinos. Sentado frente a la cámara, Palma sospecha que, "[c]omo bien lo dijo el presidente Patricio Aylwin, vamos a hacer justicia en la medida de lo posible, y esa justicia [basada en una disciplina cívica reaccionaria] también nos abarcaba al parecer" (citado en Parot). Palma intuye bien y, en pocos días, la pista del Esmeralda se transforma en el campo de batalla de una guerrilla cultural.

\section{Guerrilla en la disco}

El contenido manifiesto de entrevistas y materiales de prensa señala que Spandex surge a causa de un impasse financiero: el Gran Circo Teatro debe saldar la deuda generada por El gran circo de Chile. Época 70: Allende (1990), la entrega que sucede, sin pena ni gloria, a su taquillero debut, La Negra Ester (1988). En entrevista con el semanario The Clinic, Palma recuerda:

Había que generar las lucas [dinero]. Podía ser una completada [venta de hot-dogs] pero lo encontraba tan ordinario que le dije [a Pérez] que hiciéramos fiestas. Le dije que yo me hacía cargo y que no me hueveara. Empecé a trabajar con la actriz Titi Ramírez, con Gladys "Lola" Hervia, con la productora de moda Fernanda Zamora a quien conocía de otras dinámicas y ella me contactó con Jordi Castell, y más la gente de la productora Órbita que había conocido en el Estadio Chile [cuando Palma participa del performance que Pérez celebra para recomponer la memoria de los que allí fueron torturados durante la dictadura de Pinochet]. [Con ellos, pues,] formamos un equipo de producción. Así surge Spandex. (citado en Alvarado, par. 24)

De manera cáustica, en cambio, el contenido latente del material de prensa revela una temprana política cultural de la Concertación Democrática y cómo ella incide en la conformación de la escena teatral de la transición. Sirva trazar una escueta relación de sucesos. Tras fracasar en su búsqueda de auspicios estatales, el Gran Circo Teatro estrena La Negra Ester el viernes 9 de diciembre de 1988, en una carpa plantada en la plaza Bernardo O’Higgins, inhóspita caleta de adictos al neopreno de la comuna de Puente Alto (único municipio que atiende al llamado de la compañía). Después de seis funciones 
que congregan a más de 600 espectadores, los mismos personeros de gobierno que antes los evaden, ahora, con la venia del alcalde de Santiago Centro, el pinochetista Gustavo Alessandri, ofrecen a la compañía trasladar su espectáculo al corazón de la ciudad. Sin más, el viernes 23 de diciembre, La Época titula que, el mismo día de navidad, "[a]l Santa Lucía se cambia La Negra Ester" (Rodríguez 19).

A riesgo de pecar de paranoico, sugiero que el cambio de parecer de las autoridades obedece a un cálculo político. Nótese. Para La Negra Ester, Pérez compone un texto dramático a partir de las décimas autobiográficas homónimas de Roberto Parra Sandoval, hermano de Violeta (historia de amor entre un poeta popular, Roberto, y una prostituta, Ester, ambientada en boîtes, burdeles y hoteles galantes del puerto de San Antonio, durante la Segunda Guerra Mundial [1939-1945]). Para el montaje, en tanto, la dirección de Pérez añade teatro circo (aprendido al alero Mnouchkine), jazz guachaca o popular (interpretado en vivo por La Regia Orquesta de Cuti Aste, Álvaro Henríquez y Jorge Lobos), e iconografía popular (diseñada por Palma a partir de desechos y escombros hallados en demoliciones del mismo puerto). De la amalgama entre las décimas de Parra y teatro circo de Pérez, surge un espectáculo que es, ante todo, una indagación festiva de las estrategias culturales que artistas, cafiches, inmigrantes, marinos, policías y prostitutas de San Antonio despliegan en su sueño de ingresar, desde la periferia chilena, a la "modernidad mundial" (claro está, sueño posible antes de 1973). Así lo atestiguan los espectadores de las primeras funciones. En revista Mensaje, Juan Andrés Piña acierta con su juicio sobre el alcance nacional de La Negra Ester:

Más que una obra de teatro de hechuras relativamente tradicionales, La Negra Ester es un espectáculo en todo el sentido de la palabra [...] Lo acordes que introducen la obra son sintomáticos: las primeras notas de la canción nacional de Chile que bruscamente se interrumpen para dar paso a una suerte de jazz "[g]uachaca" [...] Este comienzo da la nota que dominará durante toda la representación: la caracterización de lo nacional (incluso la obra cierra con los últimos compases del mismo himno), tono popular y festivo, y la participación del público. (109, énfasis mío)

Alentados por esta clase de comentarios, seducidos con "la caracterización de lo nacional", sospecho que los personeros de gobierno intuyen que La Negra Ester es - como habría dicho Doris Sommer (25) - un romance nacional en ciernes; es decir, un relato que, por su asunto amoroso 
irresistible, propicia su difusión amplia y, por añadidura, la posibilidad de ser comprendido por una audiencia masiva como representación alegórica de la reconciliación entre facciones antagónicas de la historia de la nación. De ahí el supuesto de que las décimas de Parra, ambientadas en un pasado remoto (la Segunda Guerra Mundial), permitirían el reencuentro de los ciudadanos con manifestaciones artísticas valoradas en los gobiernos del Frente Popular, de la Revolución en Libertad y, por supuesto, de la Unidad Popular como señas de identidad nacional (e.g. cueca brava, jazz guachaca, poesía popular, teatro callejero), pero, sin hacer referencias explícitas a su contexto de emergencia política ni mucho menos a la razia dictatorial que, tras el golpe de 1973, aniquila a sus cultores. ${ }^{8}$

Treinta años después, dentro de este contexto, se comprende mejor la elogiosa carta que el político democratacristiano Ignacio Walker envía al diario La Época, afín al gobierno de la Concertación Democrática, luego de asistir a una función de La Negra en la cima del Santa Lucía:

Nunca imaginó don Benjamín Vicuña Mackenna que en el cerro que él diseñara (el Santa Lucía), casi un siglo más tarde se instalaría un prostíbulo con La Negra Ester; un prostíbulo al que concurrían, diariamente, coincidiendo con la puesta de sol, en una verdadera peregrinación, centenares de personas (a tablero vuelto). Menos aún pudo haber imaginado el ilustre repúblico y hombre de letras que, en ese prostíbulo, miles de chilenos se reencontrarían con sus propias raíces [situadas, claro está, mucho antes de la Unidad Popular]. Pero es que eso es lo que se siente en la obra de teatro La Negra Ester. Es un pedazo de Chile, de su música, de su idiosincrasia. Su lenguaje es nuestro lenguaje, con sus dichos, su poesía, su picardía. (7)

En la coyuntura de la transición, Walker — asesor del presidente Aylwin entre 1990 y 1993 - celebra este romance nacional y señala que "nuestro lenguaje", el de los ciudadanos de la transición, debe ser el de esa poesía popular que se construye con "dichos" y "picardía" pero sobrevive al contagio malsano con la política extremista y fratricida; por eso, se vuelca al pasado, obliterando la "beligerancia" de la historia reciente. Al evocar ese lenguaje, los miembros de la compañía "[n]os hicieron sentir que entramos en tierra

8 Juan Villegas es quien primero advierte el carácter ambivalente de La Negra Ester, quizá el único. Él opina que la "influencia [o, el impacto de Pérez] apunta [o, se debe] a su lectura de la historia, con cierta tendencia a la deshistorización y desconflictuación de la misma" (194). 
derecha", por ende, no en el territorio de las ideologías de izquierdas extremas. Gracias a este tipo de orientaciones, ofrecidas por el teatro que mira "sus propias raíces", es que, en hora buena, "empezamos a construir un futuro más nuestro" (Walker 7). ${ }^{9}$

$\mathrm{Al}$ recuperar información de prensa sobre lo que viene después de $L a$ Negra Ester para Pérez y su compañía, creo no errar con mi tesis conspirativa. Ya en 1989, el Gran Circo Teatro espera continuar recibiendo la venia del Estado y la prensa, para preparar una nueva pieza de asunto amoroso y popular, esta vez, una memoria del gobierno de Salvador Allende cuyo título abreviado es Época 70. Con este fin, Pérez construye un texto que, en sí mismo, es un osado archivo de la Unidad Popular: en él, todos los parlamentos son fragmentos de declaraciones, discursos y entrevistas en las que Allende y sus interlocutores se permiten soñar con Chile: Carlos Altamirano, Miguel Henríquez, Carlos Prats, René Schneider, Raúl Silva Henríquez y José Tohá, entre los más citados. El escenario escogido por la compañía para el estreno del montaje es el teatro Esmeralda. Para solventar los costos del proceso de producción, el mismo Pérez consigue un crédito bancario en el mercado financiero, pues confía en que el éxito de la pieza le permitirá recuperar la inversión.

Así, la primera función de Época 70 tiene lugar el martes 2 de octubre de 1990. Lamentablemente, la compañía olvida que Augusto Pinochet continúa en el cargo de comandante en jefe del Ejército y, como es de suponer, críticos y espectadores reaccionan con incomodidad ante una propuesta que, por

9 Sin proponérselo — creo yo-, La Negra Ester permite que los políticos de la concertación puedan exorcizar los conflictos que les suscitó su supuesta proximidad a otros productos culturales surgidos desde posiciones más radicales. Piénsese, sin ir más lejos, en el episodio ocurrido, meses antes, en el teatro Cariola de Santiago, en un encuentro entre trabajadores de la cultura y el entonces candidato presidencial Patricio Aylwin: mientras la actriz Ana González ofrece su discurso, irrumpen en escena las Yeguas del Apocalipsis, Francisco Casas y Pedro Lemebel. Parapetadas en el escenario, se quitan sus impermeables y se muestran travestidas como luminosas vedettes. Ante un público impávido, en el que también se cuentan los futuros presidentes de Chile, Ricardo Lagos y Eduardo Frei, las Yeguas [...] despliegan una pancarta que reza: "Homosexuales por el cambio". Lemebel recuerda: "[l]a Mariana Aylwin nos decía “ipor qué le hacen esto a mi papá? La derecha va a pensar que se nos van a meter [al gobierno] las prostitutas, los homosexuales, todo el lumpen"” (citado en Parot, énfasis mío). Hoy día, parece inquietante saber que, pese a la gran cantidad de reporteros que se encontraban en el Cariola, del escándalo solo se guarda una fotografía. Pedro Montes, de la Galería D21, hace eco de un rumor plausible: "dicen las malas lenguas que habría habido una orden de Estado para eliminar esa[s] fotos" (citado en Parot). 
frontal, se resiste a ser puesta en circulación como un romance nacional. La mañana siguiente, El Mercurio titula: "Angustiante estreno". En su crítica, Juan Antonio Muñoz esgrime:

Lo que le importa al director es el sueño de Allende y nos lo representa desde sus discursos, desde sus palabras sentidas y su palabrería. Se levanta la figura de un político, pero no la de un político cualquiera, sino la de un ser tremendamente ingenuo, siempre sobrepasado por los acontecimientos, incapaz de dominar la situación [...] Solo una pregunta queda al pasar: ¿̇es ontológicamente bueno poner en escena esto ahora? (Muñoz "Angustiante", énfasis míos)

La respuesta a la pregunta retórica planteada por Muñoz es un no rotundo. En una transición en la que los militares gobiernan junto con la concertación, reflotar la voz de los actores de la Unidad Popular, sin medicaciones alegóricas ni distanciamientos temporales, es un ejercicio que entorpece el objetivo mayor que se autoimpone la coalición de gobierno, desde Aylwin hasta Walker: transitar por "tierra derecha". Con un simple ejercicio de audiencias, Rosario Guzmán Errázuriz, columnista de La Segunda y hermana del senador asesinado, exhibe el malestar que suscita el nombre de Allende entre los líderes concertacionistas: "luego de un largo peregrinaje en que invitamos a diversos políticos [...] algunos de la Concertación [correligionarios de Aylwin, como Walker] manifestaron una decidida falta de interés por presenciar una obra que [...] no les parecía adecuada ni oportuna" (6). El silencio de los políticos anuncia, cual epígrafe de tiempos aún oscuros, el tipo de lenguajes teatrales y discursos que el Estado considera, al igual que La Negra Ester, "adecuados", "oportunos", "ontológicamente buenos". Meses después, y luego de ser vista por menos de 3000 espectadores, Época 70 sale de cartelera: el Gran Circo Teatro está quebrado:

Sí, tenemos que dejar el teatro ya que no podemos seguir pagando: en realidad, nunca hemos podido hacerlo con regularidad. El Esmeralda pertenece a un particular que lo ha pedido. La decepción, además, influyó en el ánimo de todos. Nuestro trabajo no nació de la noche a la mañana. Se gestó, tuvo un proceso, se consiguieron cosas. Realizamos una labor pedagógica y artística intensa en sectores nunca contemplados [...] Hoy sentimos que hay un gran proyecto fracasado; que todo lo que hemos hecho no sirvió para nada y que, a pesar del enorme trabajo desplegado en beneficio de muchos no obtenemos ningún reconocimiento [...] (Pérez citado en Muñoz, "Disuelve") 


\section{Universitarios, colas y punkies}

Para Palma y Pérez, Spandex es el salvavidas que permite enfrentar la miseria. Sin más, en junio de 1991, ya están sitiados en el Esmeralda:

Era la primera vez que se convocaba a tanta gente a un hueveo y la gallada empezó a producirse, a cambiar las ropas, todo muy rápido. Después de la sexta fiesta [Noche de Estrellas (8 de junio)], Pérez me invitó a almorzar y me pidió que me dedicara exclusivamente al vestuario de lo que estábamos haciendo, Ricardo II y Noche de reyes [...] Era él o Spandex, y yo seguí por Spandex. Nos cambiamos al Teatro Carrera [...] (Palma citado en Crespo 165)

Como en una saga de detectives, en esta escena, Palma ignora información decisiva. Días antes del almuerzo, Pérez recibe un llamado de un funcionario de gobierno. La amenaza es directa: si Spandex no cesa, Gran Circo Teatro perderá toda posibilidad de optar a apoyo fiscal a través del nuevo fondo gubernamental para el desarrollo de la cultura y las artes (luego llamado FONDART), cuyo primer reglamento sería publicado meses después, en 1992 (Palma citado en Crespo 165). Más adelante, Palma continúa:

[tras el alejamiento de Pérez,] Arturo Barrios [presidente] de la FECH [Federación de Estudiantes de la Universidad de Chile] se acercó a nosotros para hacer una feria de prevención de SIDA. La idea era hacer stands estilo Spandex: bien adornados y con harta osadía [...] En el escenario ya estábamos con el show del condón [...] Cuento corto: enseñé en el escenario cómo poner el condón con la boca, porque el rollo era que al momento de los qué hubo, cuando el loco se tenía que poner el condón, se le bajaba el pico, se enfriaba el cuento y la mina quedaba pagando. Entonces la propuesta fue enseñarles a las mujeres a ponerlo con la boca. Y yo, dildo en mano, mostré cómo. Fue un escándalo y, a la semana siguiente, llegaron los pacos a hablar con el viejo chico, el dueño del teatro: si nos volvía a arrendar la sala, le quitaban la patente $[\ldots]$ (Palma citado en Crespo 165-66)

El móvil de la amenaza es evidente. El gabinete de Aylwin teme la inminencia de un destape a la española, una "movida santiaguina": "[n]o querían que quedara la cagada que había quedado en España después de Franco: el destape era un problema que ellos no querían asumir y era mejor que cada uno volviera a su gueto para manejarlos separadamente" (Palma citado en Crespo 165).

Acto seguido, la Presidencia encarga un primer informe nacional sobre prácticas juveniles. De acuerdo con el Primer informe nacional de la 
juventud (1994), el Estado debe implementar un conjunto de "propuestas programáticas" que incentive "la ciudadanía juvenil" (378). El efecto colateral de estas políticas públicas es la consecuente desarticulación paulatina de colectivos contraculturales surgidos desde los márgenes de la disciplina estatal. El impacto del informe es rotundo. Desde su encargo (1991) hasta la publicación de un boletín oficial (1994), se multiplican las instancias privadas que normalizan la disidencia juvenil y promueven su conversión en un nuevo nicho de obedientes consumidores. Maquinación o azar, lo cierto es que en el periodo 1991-1992, la disolución del colectivo de los chicos del Esmeralda coincide con la inauguración de una serie de espacios "oficiales" que, alineados con el informe gubernamental, tiene como objetivo canalizar la revuelta juvenil: el diario El Mercurio inicia la publicación de la revista Zona de Contacto (1991), la Compañía Chilena de Comunicaciones funda la radio Rock \& Pop (1992) y la revista homónima (1994), el propio gobierno de Aylwin inaugura la Corporación Cultural Balmaceda 1215, desde donde ofrece talleres de artes visuales, literatura, música y teatro (1992). Con desazón, en diferentes medios, Palma comenta: "[a] Aylwin lo llamábamos 'el amigo Pato' —i [si] Fuimos muy inocentes! [...] Somos hijos de esta trampa que fue la transición, donde se impidió una movida como la española" (citado en Ramírez 37). ¿Y cómo no se iba impedir semejante desacato si — como bien observa Palma - el equilibrio cívico-militar de la transición dependía de que "cada quien [estuviera] en su [...] rincón; los colas, acá; los punkies, en su esquina; los universitarios, en sus salas?" (Palma citado en Parot).

Desalojada la trinchera de Spandex, en la década que sigue (1992-2002), "mal nos fue a todos". La TV de la transición prescinde de los servicios de Palma y, en medio de la cesantía, es diagnosticado con VIH/SIDA (octubre de 1995); sin éxito, colabora con la ONG Frena-SIDA (1997); peor, la precariedad de las terapias antirretrovirales permite que un herpes zóster le arrebate la visión (enero de 1996). Por su parte, Pérez estrena 14 piezas teatrales (pero, ninguna obtiene el mismo reconocimiento que La Negra Ester); postula a fondos públicos (pero, jamás obtiene apoyo del mentado FONDART); recupera espacios residuales (pero, no consigue recursos para conservarlos). ${ }^{10}$

10 En 1992, las deudas hacen insostenible la mantención del Esmeralda. Impedido de continuar con Spandex y sin mayor apoyo de terceros, Pérez desiste del proyecto de contar con una sala propia, asume la deuda contraída (el mentado crédito bancario) y abandona la compañía Gran Circo Teatro. En una entrevista de esa época, lamenta que la compañía "abrió muchos espacios para el trabajo artístico. Por ejemplo, el cerro Santa Lucía y el Parque Forestal. Sin 
El 3 de enero de 2002, muere a causa de una neumonía favorecida por su condición de $\mathrm{VIH}+$ y por deficiencias técnicas en el ducto respiratorio de su lecho de muerte (cama 8, Hospital San José de Santiago). ${ }^{11}$

\section{El baile de los polizontes}

Dispuestos así los hechos, no cuesta deducir por qué cae Spandex. Regreso a la última fiesta organizada por Palma y Pérez, Noche de Época: La Nuestra (22 de junio de 1991). En el escenario, Candy Dubois, artista transexual, estrena su único single: "Maten a todo el mundo hoy", canción de bases house compuesta por Andrés y Germán Bobe. En esa interpretación, La Divina, como la llaman sus admiradores, intercala arengas que conminan a los asistentes a enfrentar de manera informada al VIH/SIDA ("condón, condón, condón", exclama al final del su show). En la pista, bañados por el resplandor de las luces estroboscópicas, bailan semidesnudos Palma y Pérez. Para los chicos Spandex — ya cogidos por el $\mathrm{VIH} / \mathrm{SIDA}$ - lo que viene enseguida es un allanamiento y, después, un perpetuo deambular. $\mathrm{O}$, tal como dice la letra de la canción de la diva trans, la huida de unos polizontes urbanos "muertos, quemados, incinerados, / aplastados, destruidos, aniquilados, infectados".

Enfatizo la ironía de ese cuasi-himno generacional porque, sin el amparo de Spandex, Palma y Pérez quedan abandonados en una ciudad que vuelve a ser lo que siempre fue, un conjunto desagregado de guetos habitado por muertos vivos:

Me acuerdo de los bares, el Churrasco por ejemplo, que estaban a la orilla del cerro Santa Lucía a principios de los 9o. Cuando la loca se quedaba esperando ahí como hasta las cinco o seis de la mañana y el macho caía de

embargo, parece que esos sitios ahora están ocupados [y administrados según los planes del actual gobierno]" (C15). En 1994, el estrés de producir desde la precariedad hace que su cuerpo dé señales inequívocas del deterioro de su salud física. Entrevistado por Willy Nikiforos, responde: "[g]racias por preocuparse por mí. Yo estoy muy feliz aquí [París]. Me preocupa, eso sí, estar con la pierna enferma, ya que los médicos no saben lo que tengo" (33).

11 Meses después de su muerte (12 de abril de 2002), El Mercurio de Valparaíso avisa que el Ministerio de Salud ha presentado una denuncia ante los tribunales de justicia ya que "22 son las muertes que se produjeron en la fatídica 'cama 8' de la Unidad de Tratamientos Intensivos (UTI) del hospital San José entre agosto de 2000 y febrero de 2002" (par. 1). La denuncia del Ministerio se produce días después de que la prensa — alertada por familiares de los fallecidos - informara "de un error en la conexión de las tuberías de gas y aire [de la cama 8]. Estas [tuberías] estaban invertidas y los pacientes solo recibieron aire, mientras que entre diciembre pasado y el 23 de febrero [es decir, cuando Pérez ingresa al recinto,] los pacientes recibían aire cuando requerían oxígeno, y viceversa" (par. 2) 
curado, le chupaba el pico rapidito en el baño o a los pies del cerro. Esa era la dinámica. Creo que eso [...] [había] cambi[ado] un poco con las Spandex, que no eran [en primer lugar] una plataforma de lucha homosexual, pero estaban abiert[a]s a todos [...] (Palma citado en Crespo 171)

La apertura de Spandex permite inéditos encuentros "cara a cara", "left and right", "gay and straight" (Palma citado en Crespo 165). Esta "promiscuidad" es, precisamente, la "conducta de riesgo" que escandaliza a las autoridades de la transición y, por consiguiente, la que define el objetivo soterrado de su cruzada en contra de Spandex: desbaratar las tramas solidarias, que, desde un teatro abandonado, proveen amparo, educación, financiamiento, memoria, placer y terapias a una cofradía de universitarios, colas y punkies rebelados en contra de los bandos que los conminan a permanecer aislados.

No por azar, dentro de esa misma cofradía de polizontes, pocos meses después, comienza a circular un artículo que Néstor Perlongher publica en $E l$ Porteño de Buenos Aires: "La desaparición de la homosexualidad" (noviembre de 1991). ${ }^{12}$ Aquello que Perlongher observa para la transición argentina, bien vale para la chilena, y los polizontes así lo entienden. "Es preciso aclarar: lo que desaparece" o se castiga, en Buenos Aires o Santiago, con la coerción del Estado y la Iglesia: "no es tanto la práctica de las uniones de los cuerpos del mismo sexo genital [...] sino la fiesta del apogeo, el interminable festejo de la emergencia a [plena] luz del día" (Perlongher n.p.). O, como dirían sus lectores chilenos, el afán de transgredir la política de los guetos. Perlongher concluye:

El episodio del SIDA es el golpe de gracia, porque cambia completamente las líneas de alianza, las divisorias de aguas, las fronteras [del colectivo homosexual]. Hay sí discriminación y exclusión con respecto a los enfermos del SIDA, pero ellos — recuérdese - no son solamente maricones. Ese estigma [que les cae] tiene más que ver, parece, con el escándalo de la muerte [...] en [el escenario de] una sociedad altamente medicalizada. (n.p.)

La cita a "La desaparición de la homosexualidad" es verosímil si se consideran las conexiones de quienes componen la "red" Spandex: Andrés Pavez, cómplice de Palma y Pérez en las noches del Esmeralda, y el propio Pérez son íntimos colaboradores del principal difusor de la escritura de Perlongher en el underground santiaguino de los años noventa, Pedro Lemebel. Será Lemebel quien, ante las muertes de Pavez y Pérez, componga los más sentidos epitafios: "Dónde vamos a encontrar otra Pavez" y "Carta para Andrés (o "Tu silencio ya me dice adiós')". 
Ciertamente, los lectores chilenos — Lemebel, Pavez, Palma y Pérezcoinciden con Perlongher: con el SIDA, "empezó la teleserie pulenta" (Palma citado en Crespo 166). Incluso en ámbito teatral, supuestamente "progresista": no son pocos los actores, críticos o directores que, mientras declaran su respeto a las reivindicaciones de las minorías sexuales, manifiestan discreta reticencia ante los colegas infectados con VIH/SIDA. Para ellos, el virus no es solo sentencia de muerte sino, también, señal de que quienes lo portan "no son solamente maricones", sino que han debido tener conductas de riesgo que, por extensión, los hacen poco confiables en su quehacer profesional. El propio Palma recuerda sus rutinas tras la cesantía y el diagnóstico:

En realidad, quedé como en blanco un año entero, botado. Comiendo para no morirme y esperando morirme al otro día. De repente salía [de casa], me encontraba con gente y los comentarios eran muy bizarros [desubicados, prejuicios]. La Coca Guazzini [actriz, contemporánea suya], por ejemplo, un día se encontró conmigo y me dijo: "¡hueón, todavía estai vivo!”. (citado en Crespo 166)

Con las tramas solidarias de Spandex destruidas, los polizontes comprenden que sus cuerpos quedan a merced de las políticas públicas de la transición a la democracia; políticas que, antes que gogo dancers, los prefieren como maniquíes de la "peste rosa"; la peste a la que se arriesgan los que cruzan los límites de la sexualidad autorizada por la ley que —insisto — allí pena la sodomía con cárcel. ${ }^{13}$

Considero, pues, que la desaparición de la homosexualidad sugerida por Perlongher, y que en Chile halla su ejemplo más nítido en la censura que

13 Formulo este juicio sobre las políticas públicas, en materia de derechos sexuales, del gobierno de Aylwin, a partir de un episodio consignado en Raro: una historia gay de Chile, del ensayista chileno Óscar Contardo. En 1993, durante su visita a Copenhague, en una rueda de prensa, una periodista de un medio local pide explicaciones a Aylwin sobre las situaciones de discriminación que padece la comunidad LGTBI+ en Chile. Ante la interpelación, Aylwin responde: "[e]n Chile no hay discriminación de la índole que usted plantea en su pregunta [...]. En general, la sociedad chilena no reacciona con simpatía frente a la homosexualidad" (13). La declaración podría ser precisada con el reemplazo de "la sociedad chilena" por "las élites chilenas". Recuérdese que, meses antes (25 de febrero de 1992), Vicente Ruíz organiza un desfile de moda en el Museo Nacional de Bellas Artes en apoyo de las personas viviendo con VIH/SIDA. Al día siguiente, y apelando a la sinonimia VIH/SIDA/ homosexualidad/degeneración, La Segunda — con su estilo habitual— titula: "Barbaridad en el Bellas Artes. Grotesco 'desfile de moda' a beneficio de los enfermos de SIDA" (1). 
se cierne sobre Spandex, es consecuencia de un caso del crónico pánico a la discoteca que padecen las élites chilenas. Y ¿qué es el pánico a la discoteca? Concluyo: para mí, el pánico a la discoteca no es ni más ni menos que ese tipo particular de agorafobia o temor súbito a los espacios ajenos que altera el discurso de clérigos, empresarios, intelectuales-orgánicos, militares, políticos y torturadores todavía temerosos de aquellas celebraciones convivales que, como las fiestas o el teatro underground, facilitan la emergencia de colectivos ciudadanos contraculturales. Son estas "células" las que, con sus desacatos a las normativas del género, siempre amenazan con destruir los estrechos límites de la feble democracia cívico-militar.

\section{Obras citadas}

Alvarado, Rodrigo. "El regreso a la noche del creador de Spandex".

The Clinic Online, 28 (julio de 2014). www.theclinic.cl/2014/o7/28/

el-regreso-a-la-noche-del-creador-de-las-spandex/. Web.

Contardo, Óscar. Raro: una historia gay de Chile. Santiago: Planeta, 2011. Impreso.

Contardo, Óscar. "SIDA: una rara y persistente sospecha (los tenemos identificados)".

El Mostrador (17 de enero de 2012). m.elmostrador.cl/noticias/opinion/2012/01/17/ sida-una-rara-y-persistente-sospecha-los-tenemos-identificados/. Web.

Crespo, Octavio. "Daniel Palma: la vanguardia como adicción". Fuera del clóset, RIL, (2010): 153-74. Impreso.

Echevarría, Germán. "Importan nuevos conceptos de diversión juvenil". El Mercurio, 27 (mayo de 1991): A19. Impreso.

Guzmán Errázuriz, Rosario. "El [Gran] Circo Teatro de Chile, Época 70, Allende. Revivir la Unidad Popular: un... ¿ $\mathrm{C}^{\text {acierto }}$ artístico?". La Segunda, 9 de octubre de 1990: 6. Impreso.

Iglesias, Constanza. "Las Spandex: De frente a la noche segunda parte". Terminal: lecturas en tránsito (4 de abril de 2014). revistaterminal.cl/ web/2014/o4/las-spandex-de-frente-a-la-noche-2da-parte/. Web.

Instituto Nacional de la Juventud. Primer informe nacional de la juventud.

Instituto nacional de la juventud. Santiago: INJUV, 1994. Impreso.

"Muertes en cama 8 de hospital sumarían 22". El Mercurio de Valparaíso, 12 de abril de 2002. www.mercuriovalpo.cl/site/ edic/20020411204959/pags/20020411232615.html. Web.

Muñoz, Juan Antonio. "Angustiante estreno de El Gran Circo Teatro de Chile". El Mercurio, 3 de octubre de 1990: Cig. Impreso. 
Muñoz, Juan Antonio. "Se disuelve la compañía Gran Circo Teatro". El Mercurio, 16 de agosto de 1992: C15. Impreso.

Nikiforos, Willy. "Era inevitable el fin de la compañía". $L a$

Nación, 11 de marzo de 1994: 33. Impreso.

Parot, Carmen Luz. "Censura y género". Chile en llamas: el arte de la cesura, capítulo 2, Chilevisión (14 de octubre de 2015). Chilevisión, www.chilevision.cl/chile-en-llamas/capitulos-completos/chile-enllamas-censura-y-genero-capitulo-2/2015-10-14/215942.html. Web.

Perlongher, Néstor. "La desaparición de la homosexualidad". El Porteño 119 (noviembre de 1991). Impreso.

Piña, Juan Andrés. "La Negra Ester". Revista Mensaje 377 (1989): 9-10. Impreso.

Ramírez, Juan Carlos. "A Aylwin lo llamábamos 'El amigo Pato' [...] ¡Fuimos muy inocentes!"'. La Segunda, 22 de julio de 2015. La Segunda Online, impresa.lasegunda.com/2015/07/22/A/6 ${ }_{2} \mathrm{O}_{37} \mathrm{NE} / \mathrm{all}$. Web.

Rodríguez, Carmen. "Al Santa Lucía se cambia La Negra Ester". La Época (23 de diciembre de 1988): 19. Impreso.

Sommer, Doris. Ficciones fundacionales. 1993. Trad. José Leandro Urbina y Ángela Pérez. Bogotá: Fondo de Cultura Económica, 2004. Impreso.

Villegas, Juan. "El teatro chileno de posdictadura". Inti: Revista de Literatura Hispánica 69-70 (2009): 189-205. Impreso.

Walker, Ignacio. "La Ester y el Quilapayún". La Época, 14 de febrero de 1989: 7. Impreso. 